Canadian

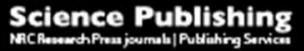

Canadian Journal of Civil Engineering Revue canadienne de génie civil

\title{
Integration of Linear Scheduling Method and the Critical Chain Project Management
}

\begin{tabular}{|r|l|}
\hline Journal: & Canadian Journal of Civil Engineering \\
\hline Manuscript ID & cjce-2017-0020.R1 \\
\hline Danuscript Type: & Article \\
\hline Complete List of Authors: & $\begin{array}{l}\text { Salama, Tarek; Concordia University, Department of Building, Civil and } \\
\text { Environmental Engineering } \\
\text { Salah, Ahmad; Imam Abdul Rahman Bin Faysal University, Department of } \\
\text { Civil and Environmental Engineering } \\
\text { Moselhi, Osama; Concordia University }\end{array}$ \\
\hline $\begin{array}{r}\text { Is the invited manuscript for } \\
\text { consideration in a Special } \\
\text { Issue? : }\end{array}$ & N/A \\
\hline Keyword: & $\begin{array}{l}\text { Linear Scheduling Method, Critical Chain Project Management, repetitive } \\
\text { scheduling }\end{array}$ \\
\hline &
\end{tabular}


1 Integration of Linear Scheduling Method and the Critical Chain Project

2

3

4

5 Department of Building, Civil and Environmental Engineering, Concordia University, Montréal,

6 Canada

7

8 E-mail addresses: ta_salam@encs.concordia.ca (Tarek Salama);

9 aaasalah@uod.edu.sa (Ahmad Salah);

10

11 Correspondent Author: Tarek Salama

12 E-mail address: ta_salam@encs.concordia.ca

13 Address: Sir George Williams Campus, 1455 De Maisonneuve Blvd. W.

14 Montreal, Quebec, Canada, H3G 1M8.

\author{
Tarek Salama, Ahmad Salah, Osama Moselhi
}

15 Telephone Number: +5145121255

\section{Management}

16

17

18

19

20

21

22 
23 Abstract: Integration of repetitive and non-repetitive scheduling methods utilizes the merits and 24 unique features of those methods. This paper presents a new scheduling method for repetitive 25 projects that integrates linear scheduling (LSM) and critical chain project management (CCPM) 26 methods. The proposed method introduces a framework for scheduling of repetitive projects;

27 accounting for constraints of resources continuity and uncertainties associated with activity 28 durations. It introduces a new buffer, named resource conflict buffer (RCB) to account for delays 29 that may occur due to conflict in controlling resources among successor and predecessor 30 activities. The developed method provides a systematic procedure for identifying several critical 31 chains to replace the visual identification method that is currently used in linear scheduling. The 32 features of the proposed method are illustrated in a case example for scheduling of repetitive 33 projects using an integration of LSM and CCPM scheduling techniques. A discussion of results 34 is performed and conclusions are drawn to highlight the features and capabilities of proposed 35 method.

36 Keywords: Linear Scheduling Method; Critical Chain Project Management; repetitive 37 scheduling. 


\section{Introduction}

47 Scheduling of construction projects can be categorized into repetitive and non-repetitive.

48 Repetitive scheduling contains cycles of repetitive activities such as those encountered in

49 housing units, highways, pipelines, and railways. Non-repetitive scheduling (network

50 scheduling) fits construction projects that do not require continuity of resources. These two types

51 of scheduling are also referred to as activity-based network scheduling and location-based

52 management scheduling (LBMS) (Kenley and Seppänen 2010). Unlike network-based

53 scheduling, LBMS is geared to maintain continuity of resources.

54 Planning and scheduling of construction projects should consider variability and uncertainty to

55 account for the dynamic nature of construction (Bakry 2014). Limited number of methods

56 incorporated uncertainty for repetitive scheduling (Bakry 2013). Simulation is utilized to account

57 for uncertainty in most of these methods while few others use buffers in linear schedules (Bakry

582013 and Slorup 2014). However, simulation models cannot maintain on its own the continuity

59 of resources for repetitive scheduling. An external algorithm has to accompany simulation

60 models to cover this shortage (Yang 2002). Existing linear scheduling methods that utilize

61 buffers either did not consider the acceleration for repetitive schedules, provide formulated

62 procedures, or use visual method for critical sequence identification. Unlike existing scheduling

63 methods, the proposed scheduling method integrates CCPM with LSM in a systematic procedure

64 that; formulates the scheduling process while maintaining continuity of resources, allocates

65 buffers while considering the required confidence level, identifies all critical chains in the

66 schedule and provides aggressive schedules that allow, where applicable, for acceleration of

67 repetitive construction activities. 


\section{Literature review}

70 Existing scheduling methods that integrate repetitive and non-repetitive scheduling are grouped

71 into two categories; deterministic and stochastic. Each category includes scheduling methods

72 with and without optimization. The capabilities and limitation of these methods are summarized

73 in Table1. Those without optimization do not make efficient utilization of resources in achieving

74 project targeted objectives, whether deterministic (Laramee 1983; Russell and Wong 1993;

75 Suhail and Neale 1994; Ammar 2013) or stochastic (Schoderbek and Digman 1967; Kankainen

76 and Seppänen 2003; Seppänen 2009; Slorup 2014; Salama et al. 2016).

77 Methods which consider optimization either focus on minimizing project duration (Selinger

78 1980, Russell and Caselton 1988), and/or cost (Moselhi and El-Rayes 1993; El-Rayes and

79 Moselhi 1998; Hassanein 2002; Hassanein and Moselhi 2004; Ranjbaran 2007). Dynamic

80 programming was utilized in optimization of this class of projects without interruptions as in

81 Selinger (1980), or with pre-determined work interruptions as in Russell and Caselton (1988) to

82 reduce project duration without considering the impact of project cost. El-Rayes (1998)

83 introduced an algorithm to account for cost in the optimization and modeled interruptions based

84 on a set of heuristic rules. Others in this group were domain specific. For example, Hassanein

85 and Moselhi (2002 and 2004) optimized schedules of highway construction considering

86 combined impacts of project cost and duration. Ranjbaran (2007) extended the work of El-Rayes

87 (1998) by presenting an object oriented model for planning, scheduling, and control of high rise

88 building without optimizing resource sharing between multiple projects. However, these methods

89 collectively neither consider uncertainty nor provide tracking and control capabilities

90 The second category of methods integrate repetitive and non-repetitive scheduling while

91 considering uncertainty associated with durations of activities. Those which utilized optimization 
92 vary in their capabilities to identify critical path, provide visualization, and/or making use of 93 critical chain management. Seppänen (2009) developed VICO as a location-based software that 94 utilizes 3D, 4D and 5D building information modelling (BIM). VICO does not have a structured 95 method for buffer sizing. It assigns buffers subjectively; larger if the predecessor activity has 96 high variability, when activities has little or no total float, or when activities are planned to be 97 performed continuously.

98 Slorup (2014) applied the buffering techniques of critical chain project management (CCPM) in 99 location based management scheduling (LBMS). However, Slorup (2014) did not present a 100 formulation for this method or a procedure for identifying critical sequence in respect to 101 constraining resources. Salama et al. (2016) suggested (BIM) based integrated framework for 102 planning and scheduling of hybrid offsite construction projects using LSM and CCPM. However, 103 this framework utilizes a visual method only for identifying critical chain.

104 Bakry et al. (2013) presented a method that consider schedule optimization to minimize project 105 duration or cost. This method produces a basic (LSM) schedule with deterministic activity 106 durations, and a buffer component that utilizes fuzzy sizing and insertion of buffers to account 107 for uncertainty. However, it is a single objective optimization method that addresses either 108 duration or cost, but not both.

109 Ghaffari and Emsley (2015) reviewed 120 studies related to CCPM and presented a 110 comprehensive overview highlighting the current status and future potential of CCPM research.

111 The application of LBMS in CCPM was cited in 21 futuristic research areas. Both LBMS and 112 CCPM utilize buffers to protect schedules in construction projects. However, unlike LBMS 113 based methods the network based CCPM methods do not consider the continuity of resources. In 114 summary, the above methods individually and /or collectively were either incapable of 
115 accounting for uncertainty or for estimating reliable buffers. The developed method considers the 116 uncertainty while utilizing linear scheduling for repetitive projects. The method is generic and 117 resource driven that integrates (LSM) and (CCPM).

\section{Method}

119 The proposed method integrates CCPM and LSM; the aggressiveness of CCPM leads to shorter 120 schedules while LSM visualizes repetitive processes and accounts for continuity of resources.

121 The framework of proposed method is illustrated in Figure (1).

\section{3.1 Calculation of aggressive and safe activity durations:}

123 Safe activity duration is defined as duration estimate that includes enough safety to protect 124 activities execution against contingencies. Aggressive activity duration is the average estimate 125 without safety time (Dilmaghani 2008). Activity aggressive duration depends on the calculation 126 of aggressive productivity rate and the constrained productivity rate (CPR) at $50 \%$ confidence

127 level of resources availability as presented in Equation (1). Activity safe duration depends on the 128 calculation of constrained activity productivity rate (CPR) at 90\% confidence level of resources 129 availability as presented in Equation (2).

130 Calculation of aggressive and safe durations using CPR leads to identification of the controlling 131 resource for each activity as presented in Equation (3). The controlling resource is defined as the 132 resource that controls the activity duration.

$135 C P R(C L)=$ Activity total quantity $($ any unit $) \times \frac{\text { availableresources output } / \text { day }(\mathrm{CL})}{\text { Total activity required resources output }}$

136 Where, 
$137 D_{i, j}(C L)$, represents the safe duration of activity " $i$ " in process " $j$ " with given confidence level 138 "CL".

$139 D_{i, j}(A G)$, represents the aggressive duration of activity "i $i$ " in process “ $j$ ”".

$140 \mathrm{CPR}_{\mathrm{i}}(\mathrm{CL})$, represents constrained productivity rate of activity " $\mathrm{i}$ " with resources availability at 141 "CL" confidence level.

142 CPRi (AG) represents constrained productivity rate of activity " $i$ " with resources availability at $14350 \%$ confidence level.

\subsection{Sequencing activities based on aggressive durations (average schedule):}

145 The aggressive schedule is sequenced using Equations 4 and 5 based on aggressive durations by 146 deducting all safety durations from activities as per the CCPM rule of aggressiveness. Goldratt 147 (1997) attributed unsatisfactory performance of schedules to two human behaviors, known as 148 Parkinson law and student's syndrome. Parkinson law implies that if execution crews complete 149 activities in less duration than scheduled, early completion of activities will not be reported. 150 Student's syndrome implies that if activities are assigned longer duration than it requires, then 151 execution crews work at a relaxed rate. Hence, schedulers avoid Parkinson law and student's 152 syndrome by deducting safety durations and if any activity is delayed then feeding and project 153 buffers absorbs this delay.

$$
\begin{aligned}
& S D_{\mathrm{i}, \mathrm{j}}(\mathrm{AG})=\operatorname{Max}\left[F D_{\mathrm{i}, \mathrm{j}-1}(\mathrm{AG}), F D_{\mathrm{i}-1, \mathrm{j}}(\mathrm{AG})\right] \\
& F D_{\mathrm{i}, \mathrm{j}}(\mathrm{AG})=S D_{\mathrm{i}, \mathrm{j}}(\mathrm{AG})+D_{\mathrm{i}, \mathrm{j}}(\mathrm{AG})
\end{aligned}
$$

\subsection{Maintaining the continuity of aggressive schedule:}

156 LSM rules are applied to maintain the continuity of resources for all activities. Figure (2)

157 illustrates the developed procedure for maintaining the continuity of resources. Russell and 
158 Wong (1993) defined work continuity as postponement for start date/time (SD) of activities until 159 continuous work is guaranteed. This rule is applied in the proposed procedure to maintain the continuity of work for all activities " $i$ " in the same process " $\mathrm{j}$ " as well as the continuity of work among consecutive processes using Equations (4) and (5). Equation (4) calculates the SD of an 162 activity " $i$ " as the maximum between the finish date (FD) of same activity "i" in preceding 163 process " $\mathrm{j}-1$ " and the FD of its preceding activity " $\mathrm{i}-1$ " in the same process " $\mathrm{j}$ " to maintain 164 continuity in the same process as well in the consecutive processes. Equation (5) calculates the 165 FD of activity "i $\mathrm{i}$ " in process " $\mathrm{j}$ ” as the sum of $\mathrm{SD}_{\mathrm{ij}}$ calculated using Equation (4) and the duration 166 of activity "i" in process " $\mathrm{j}$ " calculated using Equation (1) and (2). As long as "j" remains 167 smaller than the total number of processes (m), this procedure is repeated for all activities "i" in 168 all processes " $\mathrm{j}$ " to maintain the continuity of processes in the developed linear schedule.

\subsection{Resolving resources conflicts:}

171 Resources conflicts is an important issue in CCPM scheduling because solving these conflicts

172 changes the traditional critical path into the critical supply chain which is constrained by 173 resource limitations as shown in Figures (3) to (5). The critical path in Figure (3) including 174 activities A, B, C, F, I, and K changed into the critical chain including activities A, B, D, F, I, 175 and K. Three feeding buffers (FBs) were assigned after non- critical chains which are emerging 176 into the critical chain to absorb delay in non-critical chains without delaying the project. Project 177 buffer $(\mathrm{PB})$ is added at the end of critical sequence that has the maximum buffer to absorb the 178 possible delays of its activities.

179 However, the continuity constraint in linear scheduling should be respected. If two or more 180 sequential activities share the same controlling resource, then the priority is given to predecessor 
181 activities to respect the continuity constraint of aggressive schedule. Hence, the successor 182 activities start only if there are enough resources to ensure its continuity while logic relationships 183 between preceding and succeeding activities are respected.

184 However, if the normal productivity rate of preceding activity is equal to or larger than the 185 constrained productivity rate of the aggressive activity (CPR $\left.{ }_{A G}\right)$ then there are no residual 186 resources quantities that could be shared with the succeeding activity. In this case, starting the 187 first activity of succeeding process is related to the end of preceding process last activity as 188 presented in Equation (6). However, if the normal productivity rate of preceding activity 189 (without resources constraints) is lower than aggressive constrained productivity rate (CPR $\left.{ }_{A G}\right)$ 190 then, enough resources are available to start the succeeding activity before completion of 191 preceding activity. The overlap between the two activities is calculated using Equations (7) and 192 (8).

$193 S D_{\mathrm{i}, \mathrm{j}+1(\mathrm{AG})}=F D_{\mathrm{i}+\mathrm{n}, \mathrm{j}(\mathrm{AG})}$

$194 \mathrm{Q}_{\mathrm{R}}=\mathrm{Q}_{\mathrm{T}-\mathrm{Q}_{\mathrm{C}}}$

$195 \mathrm{O}_{\mathrm{RC}}=\mathrm{QR} / \min \left(\mathrm{CPR} \mathrm{AG}_{\mathrm{AG}}, \mathrm{PR}_{\mathrm{AG}}\right)$ for succeeding activity.

196 Where,

$197 \mathrm{Q}_{\mathrm{R}}$ : Residual quantities in preceding activity.

$198 \mathrm{Q}_{\mathrm{T}}$ : Total available quantities according to constrained activity productivity rate in preceding 199 activity.

200 QC: Resources quantities consumption during normal duration in preceding activity.

$201 \mathrm{O}_{\mathrm{RC}}$ : Overlap due to resources conflicts.

202 The variability of resource for preceding activity shifts the start of the succeeding activity by 203 creating another overlap $\left(\mathrm{O}_{\mathrm{VAR}}\right)$ between the preceding and succeeding activities. The difference 
204 between $\mathrm{O}_{\mathrm{RC}}$ and $\mathrm{O}_{\mathrm{VAR}}$ creates a resources conflict buffer (RCB) as illustrated in Equations (9) to

205 (11). RCB accounts for conflict in availability of resources for preceding and succeeding 206 activities as shown in Figure (6).

$207 \mathrm{O}_{\mathrm{VAR}}=\left(\mathrm{Q}_{50 \%}-\mathrm{Q}_{90 \%}\right) / \min \left(\mathrm{CPR} \mathrm{AG}_{\mathrm{AG}} \mathrm{PR}_{\mathrm{AG}}\right)$ for succeeding activity.

$208 \mathrm{RCB}=\mathrm{O}_{\mathrm{RC}}-\mathrm{O}_{\mathrm{VAR}}$

$209 S D_{\mathrm{i}, \mathrm{j}+1}(\mathrm{AG})=F D_{\mathrm{i}+\mathrm{n}, \mathrm{j}}(\mathrm{AG})+\mathrm{RCB}-\mathrm{O}_{\mathrm{RC}}$

210 Where,

$211 \mathrm{O}_{\text {VAR }}$ : Overlap of resources quantities variability for preceding activity.

$212 \mathrm{Q}_{50 \%}$ : quantities in preceding activity with $50 \%$ confidence in availability.

$213 \mathrm{Q}_{90 \%}$ : quantities in preceding activity with $90 \%$ confidence in availability.

214 RCB: Resources Conflict buffer.

2153.5 Identification of critical sequence:

216 Finding the critical sequence is crucial for integrating CCPM and LSM because CCPM is based

217 on identifying the critical path constrained by resources limitation, while the resources continuity

218 should be maintained according to LSM .The critical sequences for the aggressive schedule are

219 identified using the newly developed identification procedure illustrated in Figure (7).

220 The proposed procedure includes systematic steps that generate the same result of the visual

221 method for identifying critical sequence introduced by Harmelink and Rowings (1998). This

222 visual method states that critical sequence occurs where activities in consecutive processes are

223 closest to each other. This method locates visually the least distance between preceding and

224 succeeding processes to identify all critical activities. Unlike the visual method, the proposed

225 procedure provides a systematic framework for identification of all possible critical chains as 
226 shown in Figure (7). The critical links between two consecutive processes are located where SD

227 of activity $i$ in process $j+1$ equal FD of activity " $i$ ” in process “ $j$ ” as presented in Equation (12).

$228 S D_{\mathrm{i}, \mathrm{j}+1}(\mathrm{AG})=F D_{\mathrm{i}, \mathrm{j}}(\mathrm{AG})$

$229 \mathrm{i}$, the number of activity where $\mathrm{i}=1 \ldots \mathrm{n}$

$230 \mathrm{j}$, the number of activity where $\mathrm{j}=1 \ldots \mathrm{m}$

$231 \mathrm{n}$ and $\mathrm{m}$, numbers of activities and processes respectively

232 The identification procedure utilizes the onward and backward identification procedures; the 233 onward procedure identifies all the critical links between process " $\mathrm{j}$ " and " $\mathrm{j}+1$ " where $\mathrm{i}$ varies 234 from 1 to $\mathrm{n}$ and then the backward procedure (Zhang et al 2013) is initiated to identify critical 235 links between process " $\mathrm{j}$ ” and “ $\mathrm{j}+1$ ” when $\mathrm{i}$ varies from $\mathrm{n}$ to 1 as shown in Figure (7). Once all 236 the critical links among processes are identified then a set of critical sequences can be generated 237 using one critical link between two consecutive processes at a time until all the identified critical 238 links are used at least in one critical sequence using the framework presented in Figure (7).

\section{$239 \quad 3.6$ Adding feeding, resource and project buffers:}

240 Both LSM and CCPM use buffers to absorb delays of activities due to uncertainty associated 241 with productivity rates and resource availability. This fact facilitates the integration of both 242 methods but it assigns the buffer types and positions used in LSM in accordance with CCPM 243 rules. Traditional stage buffers used in LSM between different stages of work, and activity 244 buffers are included in the estimated activity time to account for variability in productivity rates. 245 However, in the proposed method, traditional buffers for LSM are replaced by CCPM feeding, 246 resource and project buffers.

247 Peer (1974) illustrated that if linear schedules are balanced to the extreme, then all activities are 248 critical. This indicates that assuming multiple critical sequences is valid. Hence each critical 
249 sequence has different project buffer based on its variability. Project buffer is added at the end of 250 critical sequence as per CCPM method, and in case of multiple critical sequences, each critical 251 sequence should have different project buffer depending on its critical activities variability. In 252 this case the project buffer is selected as the maximum buffer of all critical sequences and it is 253 calculated using Equation (13). The feeding buffers are added based on CCPM to reduce the 254 effects of delay of non-critical chains on critical chains. Feeding buffers in activity based 255 scheduling are assigned between the critical chain and non-critical chain. Figure (8) illustrates 256 the key features of CCPM scheduling in reducing activity durations, resolving resource conflicts, 257 identifying critical chains, assigning buffers (resource, feeding and project), and managing buffer 258 consumptions. Also, CCPM considers the buffers arising from the variability of "resource259 critical activities" number D1, 2, 3 and F1, 2, 3, 4, 5 as shown in Figure (9). The delay of 260 resource-critical activities delays part of the critical sequence and accordingly the project 261 completion date. Hence, the feeding buffer should be assigned at the end of resource-critical 262 activities and calculated using Equation (14). However, this causes discontinuity for activities 263 and for this reason feeding buffers in this research is assigned at the end of activities with a value 264 that accounts for variability of resource-critical activities. For example, activities D1, 2, 3 are 265 resource-critical activities and feeding buffer is assigned after D6 and not after D3 to respect the 266 continuity of activity D. Assigning project and feeding buffers at suggested locations fulfils 267 complete integration of LSM and CCPM because it respects the rules of both methods. Project 268 buffer is assigned at the end of critical sequence to absorb its variability. Feeding buffers are 269 assigned after non-critical chains emerging into critical ones to absorb non-critical chains 270 variability without delaying the project, while continuity of resources is maintained according to 271 LSM. 
272 Resource buffer included in current CCPM scheduling cannot be quantified and it acts as

273 warning for shortages in controlling resources (Goldratt 1997). It is assigned before each activity

274 on the critical chain that requires different controlling resource than its preceding activity.

275 Resource buffers, however, are different than proposed RCB because the latter is quantifiable 276 and it absorbs the delay of preceding activities due to variability of resources availability.

$$
\begin{aligned}
& \text { Project Buffer }=\sqrt{\sum_{\mathrm{P}=1}^{\mathrm{P}=\mathrm{n}}\left(\mathrm{D}_{\mathrm{P}}(\mathrm{CL})-\mathrm{D}_{\mathrm{P}}(\mathrm{AG})\right)^{2}} \\
& \text { Feeding Buffer }=\sqrt{\sum_{\mathrm{F}=1}^{\mathrm{F}=\mathrm{n}}\left(\mathrm{D}_{\mathrm{F}}(\mathrm{CL})-\mathrm{D}_{\mathrm{F}}(\mathrm{AG})\right)^{2}}
\end{aligned}
$$

277

278

279

280

281

282 283

\section{Case Example}

The numerical example presented in this paper builds upon that of Selinger (1980) for a hypothetical three span reinforced concrete bridge that has four segments (units) with five repetitive processes in each segment as shown in Figure (10). These processes are excavation, foundation, columns, beams and slabs. This example was used by other researchers deterministically (Russell and Caselton 1988, Moselhi and El-Rayes 1993, Nassar 2005, Liu and Wang 2007) and stochastically by Bakry (2014). Bakry (2014) included the uncertainty by utilizing fuzzy duration function for activities which is transformed into a deterministic duration (Dur Ev) as shown in Table 2. Then another duration is assumed based on agreement index (AI) that is assigned by the user to assess the amount of uncertainty affecting the activity being considered to account for the user desired confidence in the produced schedule.

The propsed method is applied by assuming that $D_{i, j}(A G)=\operatorname{Dur}_{E V}$ and $D_{i, j}(C L)=\operatorname{Dur}_{A I=0.9}$ to illustrate the differences between the developed method and that of Bakry (2014). In this case 
291 study, a triangular distribution is assumed for evaluating the duration of activities where Dur $\mathrm{EV}_{\mathrm{EV}}$ is 292 the mean/aggressive duration and $\operatorname{Dur}_{\mathrm{AI}=0.9}$ is the safe duration at $90 \%$ of confidence. Bakry's 293 method adds intermediate buffers at the point of contact of two critical activities as shown in 294 Figure (11). However, CCPM method emphasized that "safety durations" are between activities. 295 Though Bakry's approach focused on respecting activities continuity to the maximum by adding 296 intermediate buffers to account for the variability of different activities that may cause 297 unnecessary extended project duration. The proposed method was applied as shown in Figure 298 299 accounts for the variability of the first two resources-critical activities for columns process, and the second equals 1.8 days and it accounts for the variability of the first two resource-critical activities for slabs process. While the first three activities of beams does not have a feeding buffer because it has no variability in productivity rates. Then the project buffer of 5.45 days was added at the end of the critical sequence which is marked by dotted arrows on Figure (12). The project duration in Bakry's study was 163 days with buffers; however, the developed method led to 152.5 days including feeding and project buffers. Bakry's approach is reasonable for repetitive 307 projects that require attention towards continuity of resources to maximize the learning curve 308 effect and minimize equipment idle time. Assumed intermediate buffers absorb the delay of 309 critical sequence. However, this delay may not happen, rendering intermediate buffers is 310 redundant. The proposed method, however, overcomes the method introduced by Bakry (2014) 311 since it implicitly allows for acceleration of construction schedule where applicable.

312 The developed method introduces another feature of identifying multiple critical sequences then to add feeding and project buffers. As an illustration for this feature, it was assumed that the 
314 duration of the second activity $\mathrm{D}_{\mathrm{i}, \mathrm{j}}(\mathrm{AG})$ of earthmoving is changed from 15.5 to 19.5 days while $315 D_{i, j}(C L)$ changed from 16.6 to 20.5. A different critical sequence is shown in Figure (13) that 316 includes the second activity of earthmoving and excludes the first activity of foundation. Another 317 feeding buffer is added as well at the end of foundation activity to account for the variability of 318 the first activity of foundation with a value of 2.4 days. The project buffer changed as a result 319 from 5.45 to 5.56 days to account for the variability of the new critical sequence, and the new 320 project duration changed from 152.5 to 155.16 days. Accordingly, the project total duration is $321 \quad 155.16$.

322 The constraining resource is another feature of the developed method to identify the longest 323 critical sequence constrained by resources while respecting resources continuity constraint. The 324 available output of controlling resources for each activity were assumed as shown in Table 3 325 with $50 \%$ and $90 \%$ confidence rates. The total required resources output for all bridge sections 326 are calculated using the following equations.

327 Activities quantities are illustrated in Table 4 as well as the crew output/ productivity rate at $50 \%$ 328 and $90 \%$ confidence rate (Bakry 2014). Using CPR (50\%) and CPR (90\%) the new activities 329 durations are calculated using equations 1 and 2, and then the new critical sequence is identified 330 using the developed method as shown in Figure (14). The changed critical sequence from that 331 shown in Figure (14) due to resources constraints in foundation, columns, beams and slabs 332 activities. The project buffer value and the total project duration changed also to 12.8 days and 333254.26 days, respectively. The RCB is calculated to be 3.36 days, while the overlap due to 334 resources conflict is 6.73 days and the overlap due to resources quantities variability is 3.36 days. $335 \mathrm{RCB}$ is allocated after the start of beams process as shown in Figure (14). In addition to RCB, 336 three resource buffers are assigned on the critical sequence which are shown as stars when 
337 controlling resource changes from preceding to succeeding critical activity. These buffers are 338 assigned at the start of first activity of foundation, last activity of columns, and first activity of 339 slabs respectively in accordance with the CCPM theory.

340 It was assumed to calculate resources outputs using the following equations:

341 Total required gravel outputs $=0.77 \times$ Total foundation quantities.

342 Total required sand outputs $=0.4 \times$ Total columns quantities.

343 Total required reinforcing steel outputs $=100 \mathrm{~kg} \times$ Total beams quantities.

344 Total required cement outputs $=350 \mathrm{~kg} \times$ Total slabs quantities.

\section{Discussion and conclusions}

347 This paper introduces a newly developed method that integrates LSM and CCPM scheduling 348 methods. The method is capable of (1) respecting the continuity constraint required by LSM, (2)

349 reducing project duration using CCPM aggressiveness, (3) identifying multiple critical sequences 350 which are constrained by controlling resources, and (4) allocating project buffer and feeding 351 buffers at the end of the longest critical chains and between non-critical chains emerging into 352 critical ones based on CCPM. It also introduces "resource conflict buffer" to account for delays 353 that may occur due to variability in resource availability. The proposed method formulates the 354 scheduling procedure that integrates LSM with CCPM, allocates buffers that considers the 355 confidence level in durations, and identifies critical sequence in a systematic way that facilitates 356 the automation of the proposed method.

357 This integration utilises the aggressiveness of CCPM to reduce project durations while respecting 358 the resource continuity as in LSM. Constraining resources changes the critical sequence and 359 project duration. It is important to identify multiple critical sequences that may change the 
360 project duration based on variability of their respective critical sequence activities. The case

361 example demonstrates the applicability and illustrates the key features of the proposed method in

362 scheduling repetitive construction projects. However, further investigations may highlight

363 potential improvements that may help to make the proposed method more generic and to

364 facilitate its application on other types of projects. The future work is to integrate the developed

365 method with a monitoring and control technique that identifies and control the potential

366 discontinuities during the execution phase of repetitive construction projects.

367

368

References

369

370

Ammar, M. 2013. LOB and CPM Integrated Method for Scheduling Repetitive Projects. J. Constr. Eng. Manage., 10.1061/ (ASCE) CO.1943-7862.0000569, 44-50.

Bakry, I. Moselhi, O. and Zayed, T. 2013. Fuzzy Scheduling of Repetitive Construction Projects. Proceedings of the 30rd International Symposium on Automation and Robotics in Construction (ISARC 2013), Montreal, Canada.

Bakry, I. 2014. Optimized Scheduling of Repetitive Construction Projects under Uncertainty. PhD thesis, Department of Building, Civil and Environmental Engineering, Concordia University, Montreal, Canada.

Dilmaghani, F. 2008. Critical Chain Project Management (CCPM) at Bosch Security Systems

El-Rayes, K. and Moselhi, O. 1998. Resource-driven scheduling of repetitive activities. Journal of Construction Management and Economics Vol. 16, Iss. 4. 
382

383

384

385

386

387

388

389

390

391

392

393

394

395

396

397

398

399

400

401

402

403

El-Rayes, K. 2001. Object-Oriented Model for Repetitive Construction Scheduling. J. Constr. Eng. Manage., 10.1061/ (ASCE) 0733-9364(2001)127:3(199), 199-205.

Ghaffaria, M., and Emsley, M. 2015. Current status and future potential of the research on Critical Chain Project Management. Surveys in Operations Research and Management Science Journal. 20, 43-54.

Goldratt, E.M., 1997. Critical Chain, North River Press, New York.

Harmelink, D. J., and Rowings, J. E. 1998. Linear scheduling model: Development of controlling activity path. Journal of Construction Engineering and Managment, ASCE, 124(4), 263-268.

Hassanein, A. 2002. Planning and scheduling highway construction using GIS and dynamic programming. PhD Dissertation, Concordia University, Montreal, Quebec.

Hassanein, A. and Moselhi, O. 2004. Planning and Scheduling Highway Construction. J. Constr. Eng. Manage., 10.1061/ (ASCE) 0733-9364(2004)130:5(638), 638-646.

Kankainen, J. and Seppänen, O. 2003. A Line-of-Balance Based Schedule Planning and Control System. Proceedings of the Eleventh Annual Conference of the International Group for Lean Construction (IGLC-11). Blacksburg, Virginia.

Kenley, R. and Seppänen, O. 2010. Location- Based Management for Construction Planning, scheduling and control, Spon Press.

Laramee, J. 1983. A planning and scheduling system for high-rise building construction. Master of Engineering thesis, Department of Building, Civil and Environmental Engineering, Concordia University, Montreal, Canada.

Leach, L.P. 2000. Critical Chain Project Management, Artech House, ISBN 1-58053-074-5. 
404 Liu, S. and Wang, C. 2007. Optimization model for resource assignment problems of linear 405 construction projects. Journal of Automation in Construction, 16(4), 460-73.

406 407 408 409 410

Moselhi, O., and El-Rayes, K. 1993. Scheduling of repetitive projects with cost optimization.” Journal of Construction Engineering and Management, 119(4), 681- 697.

Nassar, K. 2005. Evolutionary optimization of resource allocation in repetitive construction schedules. Journal of Information Technology in Construction, 10, 265-273.

Peer, S. 1974. Network Analysis and Construction Planning. Journal of the Construction Division, ASCE, 100(CO3): 203-210.

Ranjbaran, A. 2007. Planning and control of high-rise building construction. Master of Science Thesis, Department of Building, Civil and Environmental Engineering, Concordia University, Montreal, Canada.

Russell, A. D., and Caselton, W. F. 1988. Extensions to linear scheduling optimization.” Journal of Construction Engineering and Management, 114(1), 36- 52.

Russell, A. and Wong, W. 1993. New Generation of Planning Structures. J. Constr. Eng. Manage., 10.1061/ (ASCE) 0733-9364(1993)119:2(196), 196-214.

Salama, T., Salah, A. and Moselhi, O. 2016. Alternative Scheduling and Planning Processes for Hybrid Offsite Construction, Proceedings of the 33rd International Symposium on Automation and Robotics in Construction (ISARC 2016), Auburn, Alabama, USA.

Schoderbek, P. P. and Digman, L. A. 1967. Third Generation in PERT Systems. Academy of Management Journal, 195-200.

Selinger, S. 1980. Construction planning for linear projects. Journal of the Construction Division, 106(CO2), 195-205. 
426 Seppänen, O. 2009. Empirical research on the success of production control in building 427 construction projects. PhD thesis, The Faculty of Engineering and Architecture, Helsinki

428 University.

429 Slorup, C. B. 2014. Applying critical chain buffer management theory in location-based 430 management. Construction Management and Economics Journal, 32:6, 506-519.

431 Suhail, S. and Neale, R. 1994. CPM/LOB: New Methodology to Integrate CPM and Line of Balance. J. Constr. Eng. Manage., 10.1061/ (ASCE) 0733-9364(1994)120:3(667), 667684.

434 Yang, I. 2002. Repetitive project planner: Resource-driven scheduling for repetitive construction 435 projects. PhD Dissertation, University of Michigan, Michigan.

436 Zhang, L., Pan, C. and Zou, X., 2013. Criticality comparison between the repetitive scheduling 437 method and the network model. Journal of Construction Engineering and Management, $438 \quad$ 139(10), p.06013004. 


\section{Table 1 Features of integration methods}

\begin{tabular}{|c|c|c|c|c|c|c|c|c|c|c|c|c|c|c|}
\hline \multicolumn{15}{|c|}{ Reference } \\
\hline Criteria & 1 & 2 & 3 & 4 & 5 & 6 & 7 & 8 & 9 & 10 & 11 & 12 & 13 & 14 \\
\hline Deterministic & $\mathrm{N}$ & $\bar{Y}$ & $\bar{Y}$ & $\mathrm{Y}$ & $\bar{Y}$ & $\bar{Y}$ & $\bar{Y}$ & $\mathrm{Y}$ & $\mathrm{N}$ & $\bar{Y}$ & $\mathrm{~N}$ & $\mathrm{Y}$ & $\mathrm{N}$ & $\mathrm{N}$ \\
\hline Stochastic & $\bar{Y}$ & $\mathrm{~N}$ & $\mathrm{~N}$ & $\mathrm{~N}$ & $\bar{N}$ & $\bar{N}$ & $\bar{N}$ & $\mathrm{~N}$ & $\mathrm{Y}$ & $\mathrm{N}$ & $\mathrm{Y}$ & $\mathrm{N}$ & $\mathrm{Y}$ & $\bar{Y}$ \\
\hline Optimized & $\mathrm{N}$ & $\mathrm{Y}$ & $\mathrm{N}$ & $\mathrm{Y}$ & $\bar{N}$ & $\bar{N}$ & $\bar{Y}$ & $\bar{Y}$ & $\mathrm{~N}$ & $\bar{Y}$ & $\mathrm{~N}$ & $\mathrm{~N}$ & $\mathrm{Y}$ & $\mathrm{N}$ \\
\hline $\begin{array}{c}\text { Identify } \\
\text { critical path } \\
\text { for repetitive } \\
\text { activities }\end{array}$ & $\mathrm{N}$ & $\mathrm{N}$ & $\mathrm{N}$ & $\mathrm{N}$ & $\mathrm{Y}$ & $\mathrm{N}$ & $\mathrm{N}$ & $\mathrm{Y}$ & $\mathrm{N}$ & $\mathrm{N}$ & $\mathrm{Y}$ & $\mathrm{N}$ & $\mathrm{Y}$ & $\mathrm{N}$ \\
\hline $\begin{array}{c}\text { Allow for } \\
\text { interruptions }\end{array}$ & $\mathrm{N}$ & $\mathrm{N}$ & $\mathrm{N}$ & $\mathrm{Y}$ & $\mathrm{Y}$ & $\mathrm{N}$ & $\mathrm{Y}$ & $\mathrm{N}$ & $\mathrm{Y}$ & $\mathrm{Y}$ & $\mathrm{Y}$ & $\mathrm{N}$ & $\mathrm{N}$ & $\mathrm{N}$ \\
\hline $\begin{array}{c}\text { 3D } \\
\text { Visualization }\end{array}$ & $\mathrm{N}$ & $\mathrm{N}$ & $\mathrm{N}$ & $\mathrm{N}$ & $\mathrm{N}$ & $\mathrm{N}$ & $\mathrm{N}$ & $\mathrm{Y}$ & $\mathrm{N}$ & $\mathrm{N}$ & $\mathrm{Y}$ & $\mathrm{N}$ & $\mathrm{N}$ & $\mathrm{N}$ \\
\hline $\begin{array}{c}\text { Buffer } \\
\text { modeling }\end{array}$ & $\mathrm{N}$ & $\mathrm{N}$ & $\mathrm{N}$ & $\mathrm{N}$ & $\mathrm{N}$ & $\mathrm{N}$ & $\mathrm{N}$ & $\mathrm{N}$ & $\mathrm{Y}$ & $\mathrm{N}$ & $\mathrm{Y}$ & $\mathrm{N}$ & $\mathrm{Y}$ & $\mathrm{Y}$ \\
\hline $\begin{array}{l}\text { Learning curve } \\
\text { effect }\end{array}$ & $\mathrm{Y}$ & $\mathrm{N}$ & $\mathrm{Y}$ & $\mathrm{N}$ & $\mathrm{N}$ & $\mathrm{N}$ & $\mathrm{Y}$ & $\mathrm{Y}$ & $\mathrm{N}$ & $\mathrm{Y}$ & $\mathrm{N}$ & $\mathrm{N}$ & $\mathrm{N}$ & $\mathrm{N}$ \\
\hline $\begin{array}{c}\text { Typical } \\
\text { activities only }\end{array}$ & $\mathrm{N}$ & $\mathrm{N}$ & $\mathrm{Y}$ & $\mathrm{N}$ & $\mathrm{N}$ & $\mathrm{Y}$ & $\mathrm{N}$ & $\mathrm{N}$ & $\mathrm{N}$ & $\mathrm{N}$ & $\mathrm{N}$ & $\mathrm{Y}$ & $\mathrm{N}$ & - \\
\hline $\begin{array}{l}\text { Considers cost } \\
\& \text { time } \\
\text { constraints }\end{array}$ & $\mathrm{N}$ & $\mathrm{N}$ & $\mathrm{N}$ & $\mathrm{N}$ & $\mathrm{N}$ & $\mathrm{N}$ & $\mathrm{Y}$ & $\mathrm{Y}$ & $\mathrm{N}$ & $\mathrm{Y}$ & $\mathrm{Y}$ & $\mathrm{N}$ & $\mathrm{Y}$ & $\mathrm{N}$ \\
\hline $\begin{array}{c}\text { Domain of } \\
\text { applications }\end{array}$ & $\begin{array}{c}\text { Manufacturing } \\
\text { of missiles }\end{array}$ & Bridges & $\begin{array}{l}\begin{array}{l}\text { High } \\
\text { rise } \\
\text { building }\end{array} \\
\end{array}$ & Bridges & General & General & $\begin{array}{l}\text { Housing projects, } \\
\text { bridges and } \\
\text { Highways. }\end{array}$ & $\begin{array}{c}\text { Highway } \\
\text { construction }\end{array}$ & General & $\begin{array}{l}\text { High rise } \\
\text { building }\end{array}$ & General & General & $\begin{array}{l}\text { Bridges and } \\
\text { Highways. }\end{array}$ & General \\
\hline
\end{tabular}


Table 2 DurEV and DurAI for Bridge segments (Bakry 2014)

\begin{tabular}{l|c|c|c|c|c|c|c|c}
\hline \multirow{2}{*}{ Activity } & \multicolumn{2}{|c|}{ Unit 1 } & \multicolumn{2}{c|}{ Unit 2 } & \multicolumn{2}{c|}{ Unit 3 } & \multicolumn{2}{c}{ Unit 4 } \\
\cline { 2 - 9 } & DurEV & DurAI=0.9 & DurEV & DurAI=0.9 & DurEV & DurAI=0.9 & DurEV & DurAI=0.9 \\
\hline Earthmoving & 12.4 & 13.2 & 15.5 & 16.6 & 10.8 & 11.5 & 16.6 & 17.7 \\
\hline Foundation & 19.5 & 21.9 & 20.3 & 22.9 & 17.8 & 20 & 16.9 & 19 \\
\hline Columns & 19.1 & 21 & 15.8 & 16.9 & 22.5 & 25 & 18.6 & 20.3 \\
\hline Beams & 15 & 15 & 16.3 & 16.3 & 17.8 & 17.8 & 14.1 & 14.1 \\
\hline Slabs & 0 & 0 & 17.3 & 18.7 & 14.3 & 15.5 & 18.1 & 19.7 \\
\hline
\end{tabular}


Table 3 Controlling resources availability.

\begin{tabular}{|c|c|c|c|c|c|c|c|}
\hline \multirow[t]{2}{*}{ Activity } & \multirow[t]{2}{*}{$\begin{array}{l}\text { Controlling } \\
\text { resources }\end{array}$} & \multirow{2}{*}{$\begin{array}{l}\text { Available } \\
\text { Resources } \\
\text { output/ } \\
(\mathbf{5 0 \%}) \\
\text { confidence }\end{array}$} & \multirow{2}{*}{$\begin{array}{l}\text { Available } \\
\text { Resources } \\
\text { output/ } \\
(90 \%) \\
\text { confidence }\end{array}$} & \multicolumn{4}{|c|}{ Total required resources output } \\
\hline & & & & Section 1 & Section 2 & Section 3 & Section 4 \\
\hline Excavation & Excavators & $\begin{array}{c}3 \\
\text { excavators } \\
\text { (23.33 ea. } \\
\text { m3/day) }\end{array}$ & $\begin{array}{c}3 \\
\text { excavators } \\
\text { (20 ea. } \\
\text { m3/day) }\end{array}$ & 1147 & 1434 & 994 & 1529 \\
\hline $\begin{array}{l}\text { Foundation } \\
\text { (m3/day) }\end{array}$ & Gravel & 27 & 23.1 & 794.6 & 829.3 & 765.4 & 689.9 \\
\hline $\begin{array}{l}\text { Columns } \\
\text { (m3/day) }\end{array}$ & Sand & 2.4 & 2.3 & 41.6 & 34.4 & 51.6 & 40 \\
\hline $\begin{array}{l}\text { Beams } \\
\text { (m3/day) }\end{array}$ & Sand & 2.4 & 2.3 & 34 & 36.8 & 40.4 & 32 \\
\hline $\begin{array}{l}\text { Slabs } \\
\text { (kg/day) }\end{array}$ & Cement & 2100 & 1750 & 0 & 48300 & 39900 & 50750 \\
\hline
\end{tabular}


Table 4 Activities quantities and productivity rates.

\begin{tabular}{|c|c|c|c|c|c|c|c|c|}
\hline \multirow[t]{2}{*}{ Activity } & \multicolumn{4}{|c|}{ Quantities (m3) } & \multirow{2}{*}{$\begin{array}{l}\text { Average } \\
\text { Crew } \\
\text { Output } \\
\text { PR } \\
(50 \%) \\
\text { m3/day }\end{array}$} & \multirow{2}{*}{$\begin{array}{l}\text { Crew } \\
\text { Output } \\
\text { PR } \\
(90 \%) \\
\text { m3/day }\end{array}$} & \multirow{2}{*}{ 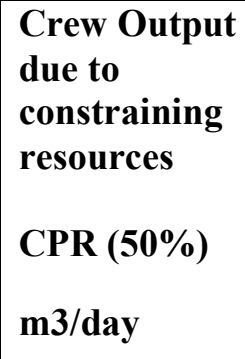 } & \multirow{2}{*}{ 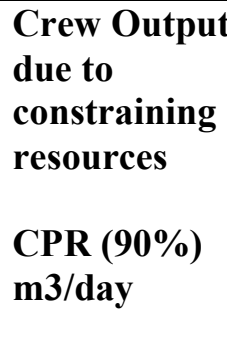 } \\
\hline & $\begin{array}{c}\text { Section } \\
1\end{array}$ & Section 2 & Section 3 & Section 4 & & & & \\
\hline Excavation & 1147 & 1434 & 994 & 1529 & 92.29 & 86.52 & 70 & 60 \\
\hline Foundation & 1032 & 1077 & 943 & 896 & 52.99 & 47.12 & 35 & 30 \\
\hline Columns & 104 & 86 & 129 & 100 & 5.5 & 5 & 6 & 5.75 \\
\hline Beams & 85 & 92 & 101 & 80 & 5.66 & 5.66 & 6 & 5.75 \\
\hline Slabs & 0 & 138 & 114 & 145 & 7.98 & 7.36 & 6 & 5 \\
\hline
\end{tabular}




\section{List of figures}

Fig. 1. The proposed method for integrating LSM and CCPM.

Fig. 2. Maintaining the continuity of aggressive schedule.

Fig. 3. Critical path for a network before resolving resources conflict.

Fig. 4. Resolving resource conflict.

Fig. 5. Critical Supply Chain after resolving resource conflict.

Fig. 6. Identifying Resource Conflict Buffer (RCB).

Fig. 7. The proposed Identification process for critical sequence.

Fig. 8. Key features of the critical chain project management system requirements.

Fig. 9. Identification of resource-critical activities.

Fig. 10. Three Span RC Bridge.

Fig. 11. Defuzzified Schedule with Buffers.

Fig. 12. Integrated LSM and CCPM schedule.

Fig. 13. Critical sequence.

Fig. 14. Critical sequence based on resources constraints. 


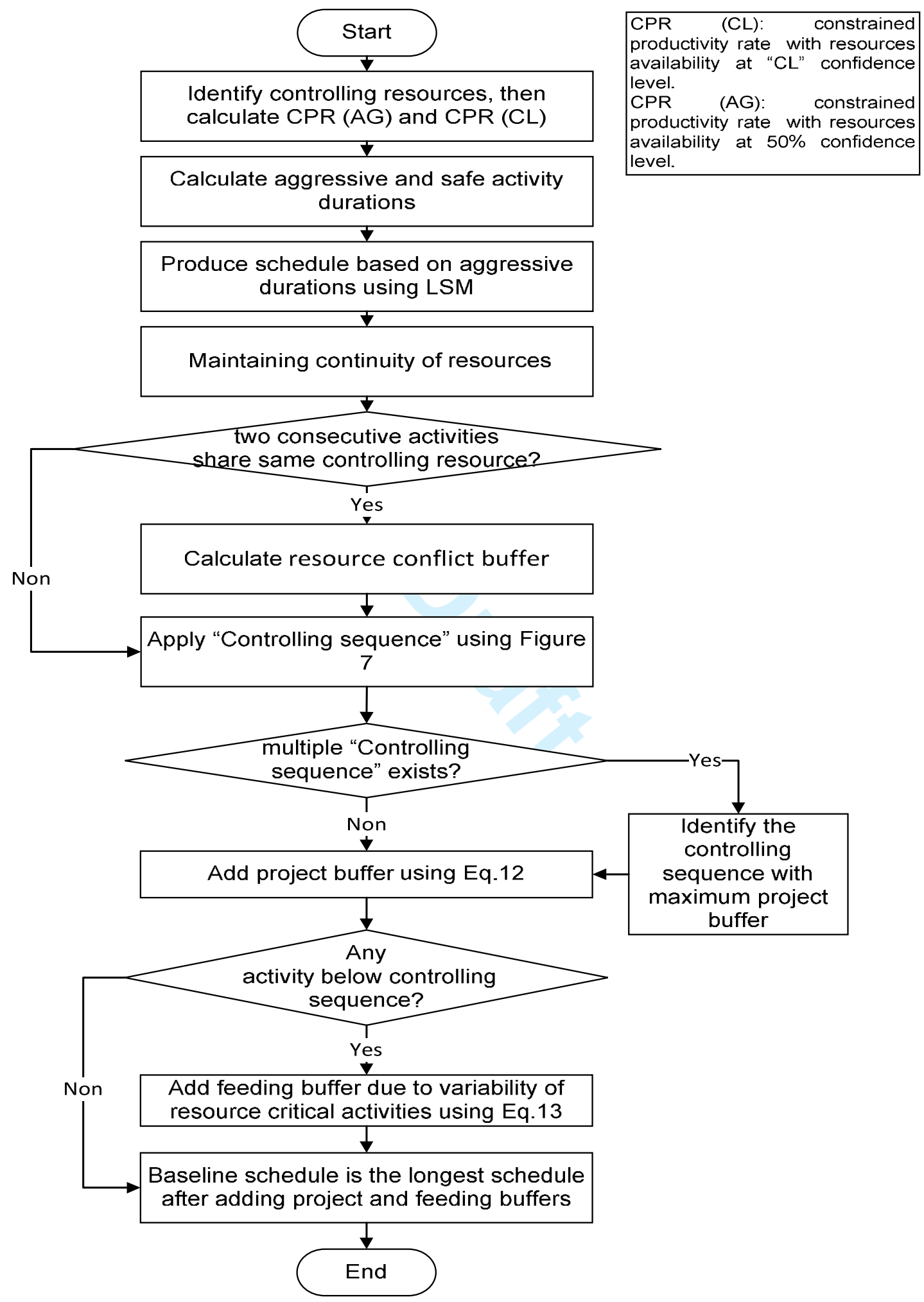

Figure 1: The proposed method for integrating LSM and CCPM. 


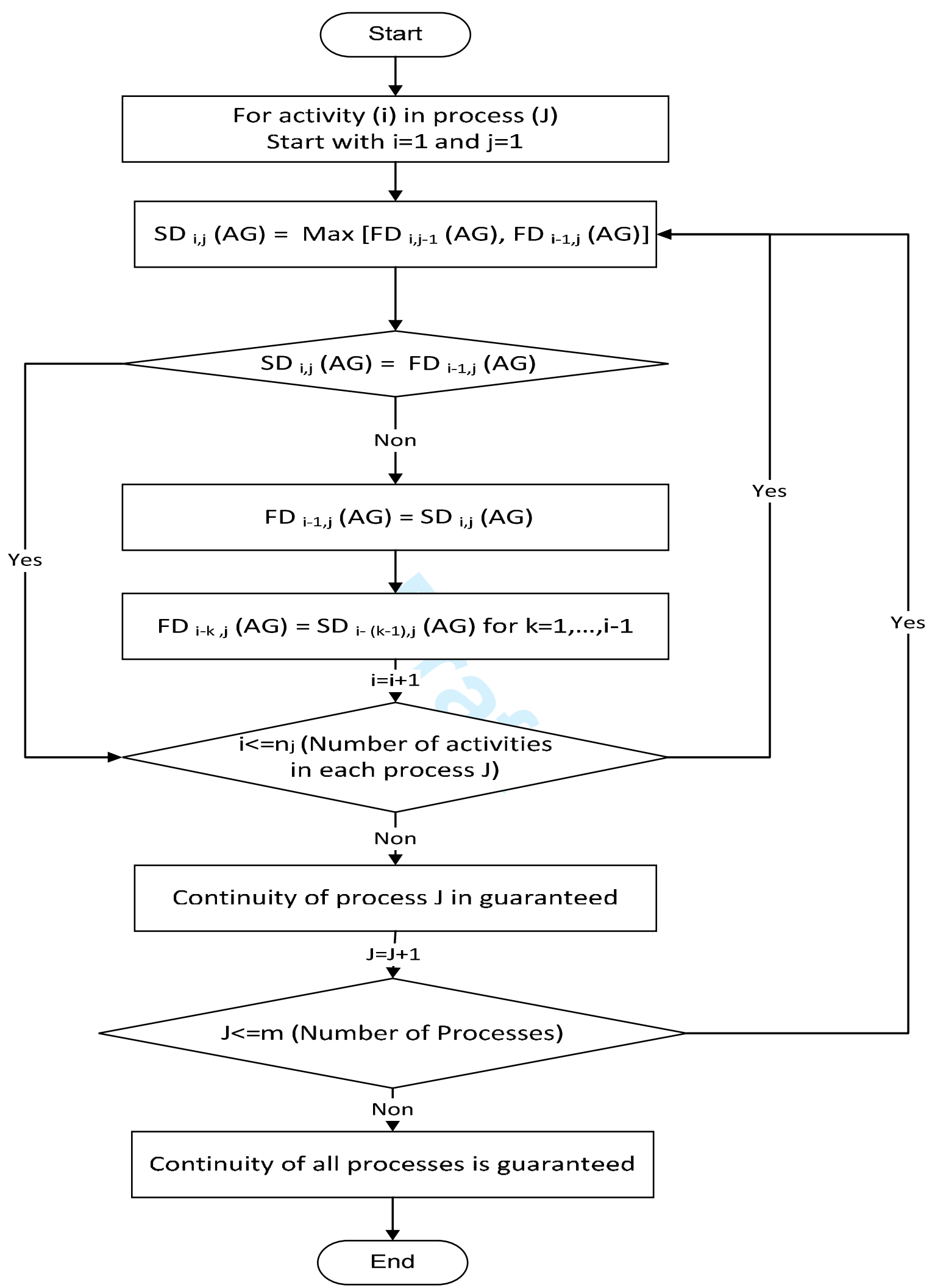

Figure 2: Maintaining the continuity of aggressive schedule. 


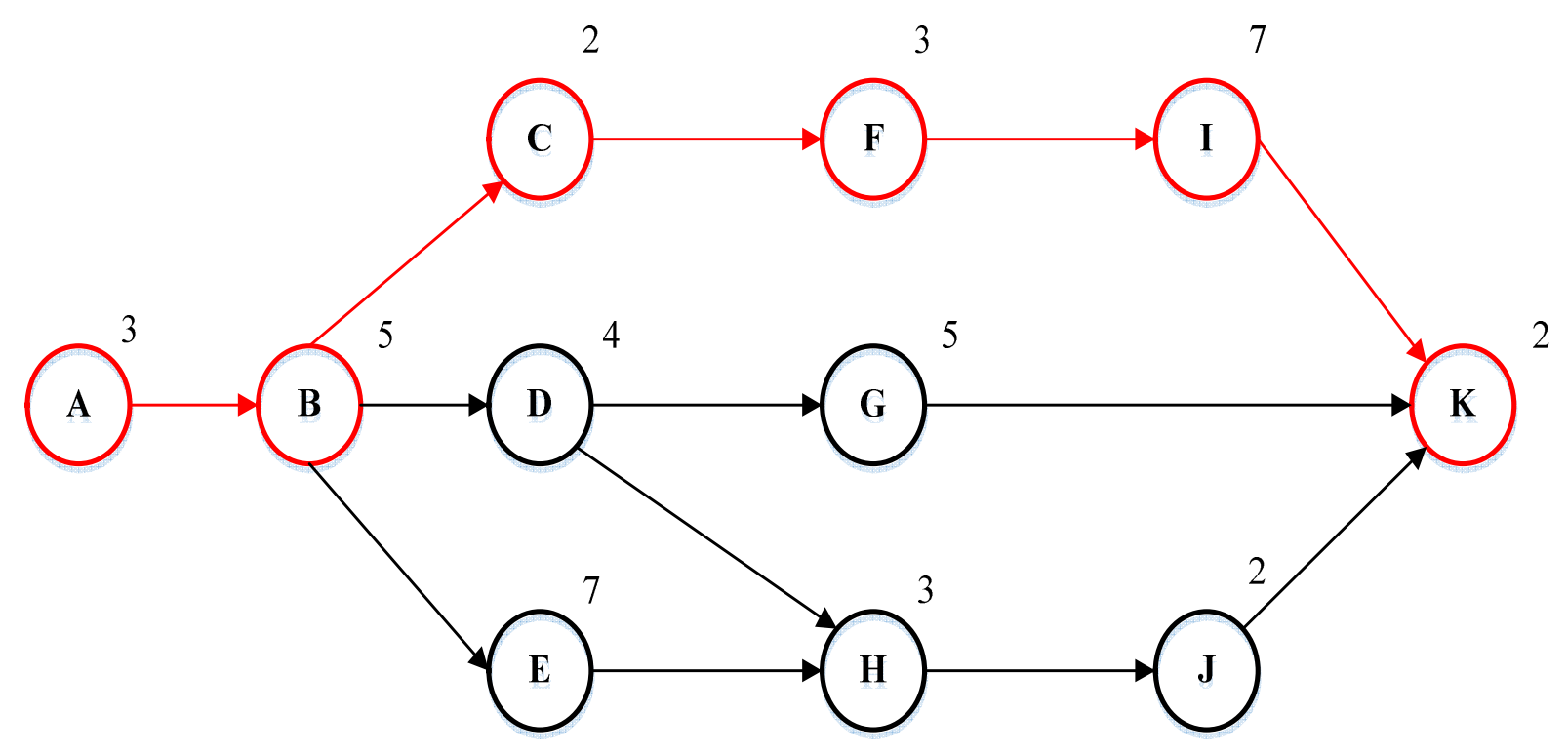

Figure 3: Critical path for a network before resolving resources conflict. 

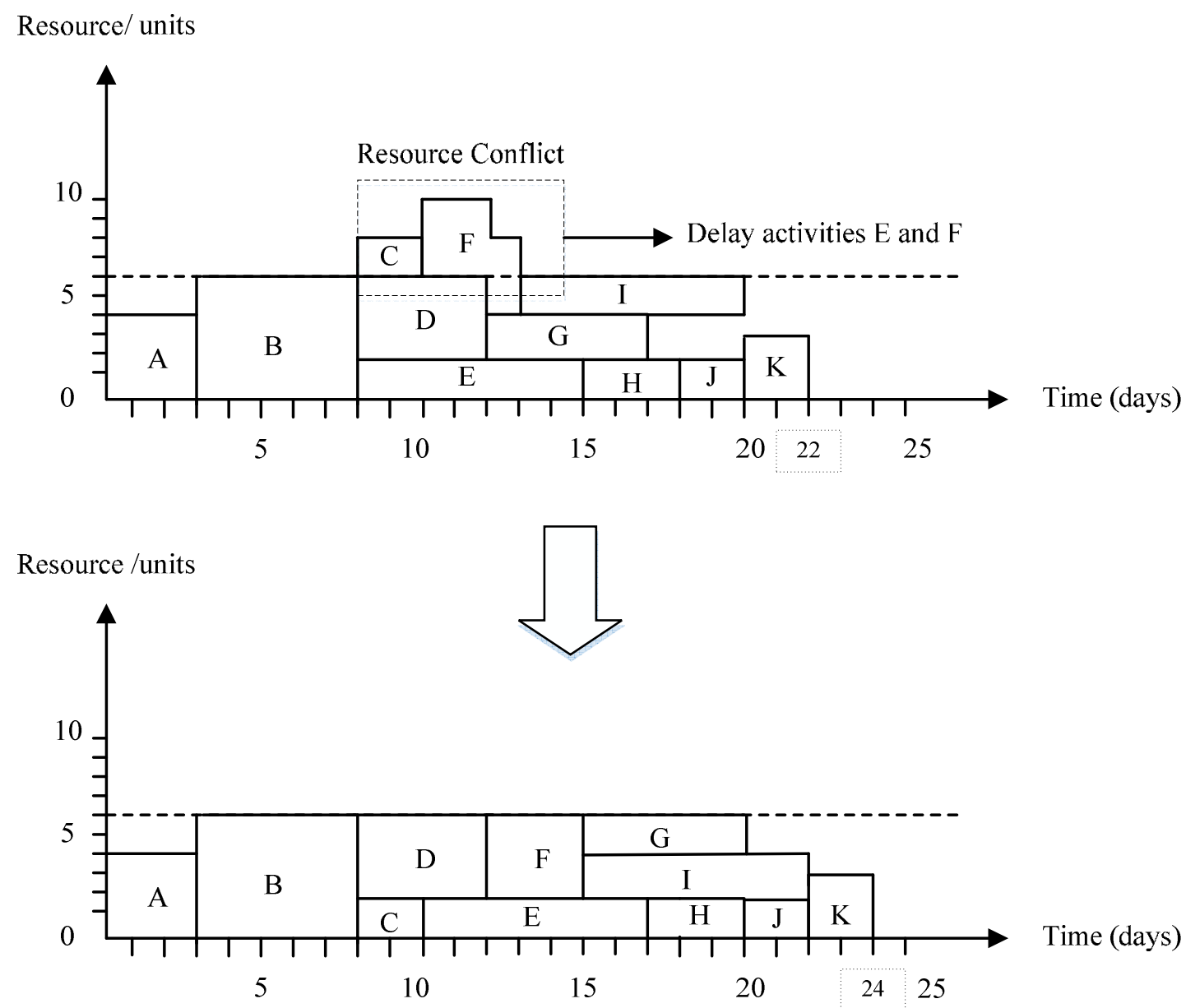

Figure 4: Resolving resource conflict. 


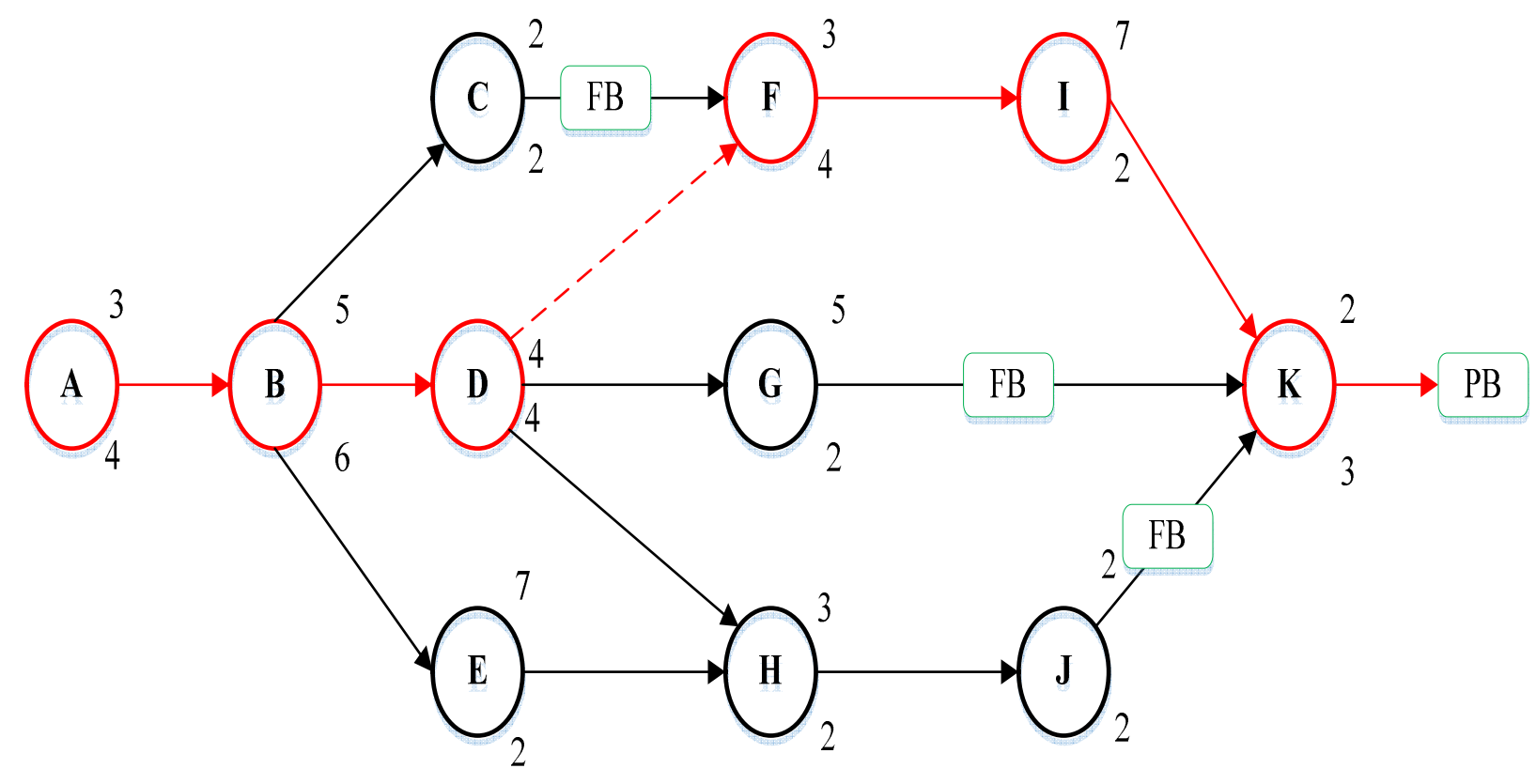

Figure 5: Critical Supply Chain after resolving resource conflict. 


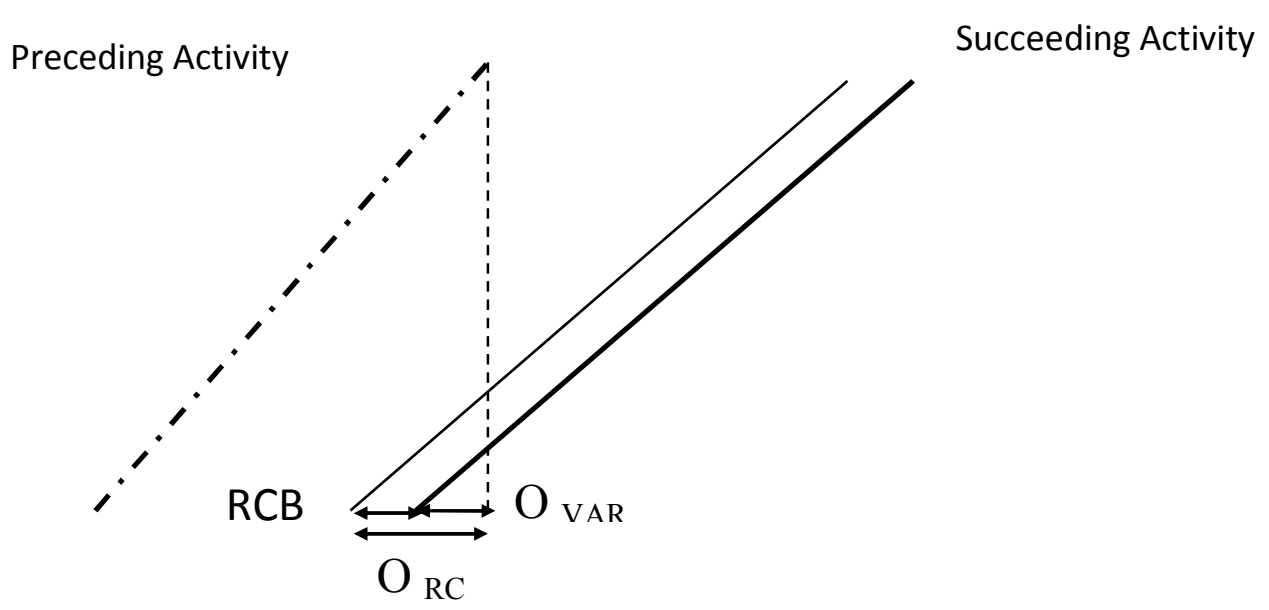

Figure 6: Identifying Resource Conflict Buffer (RCB). 


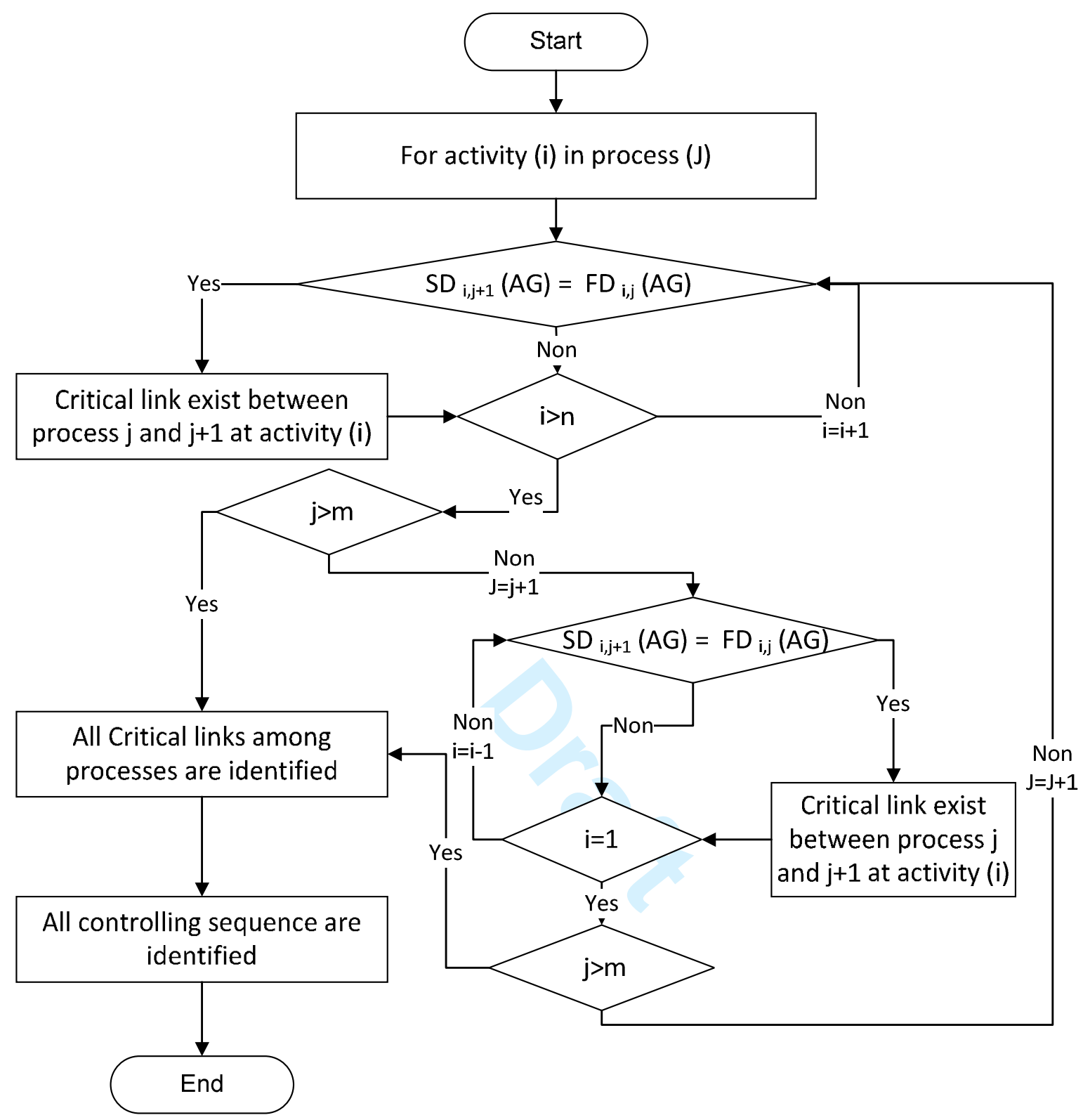

Figure 7: The proposed Identification process for critical sequence. 


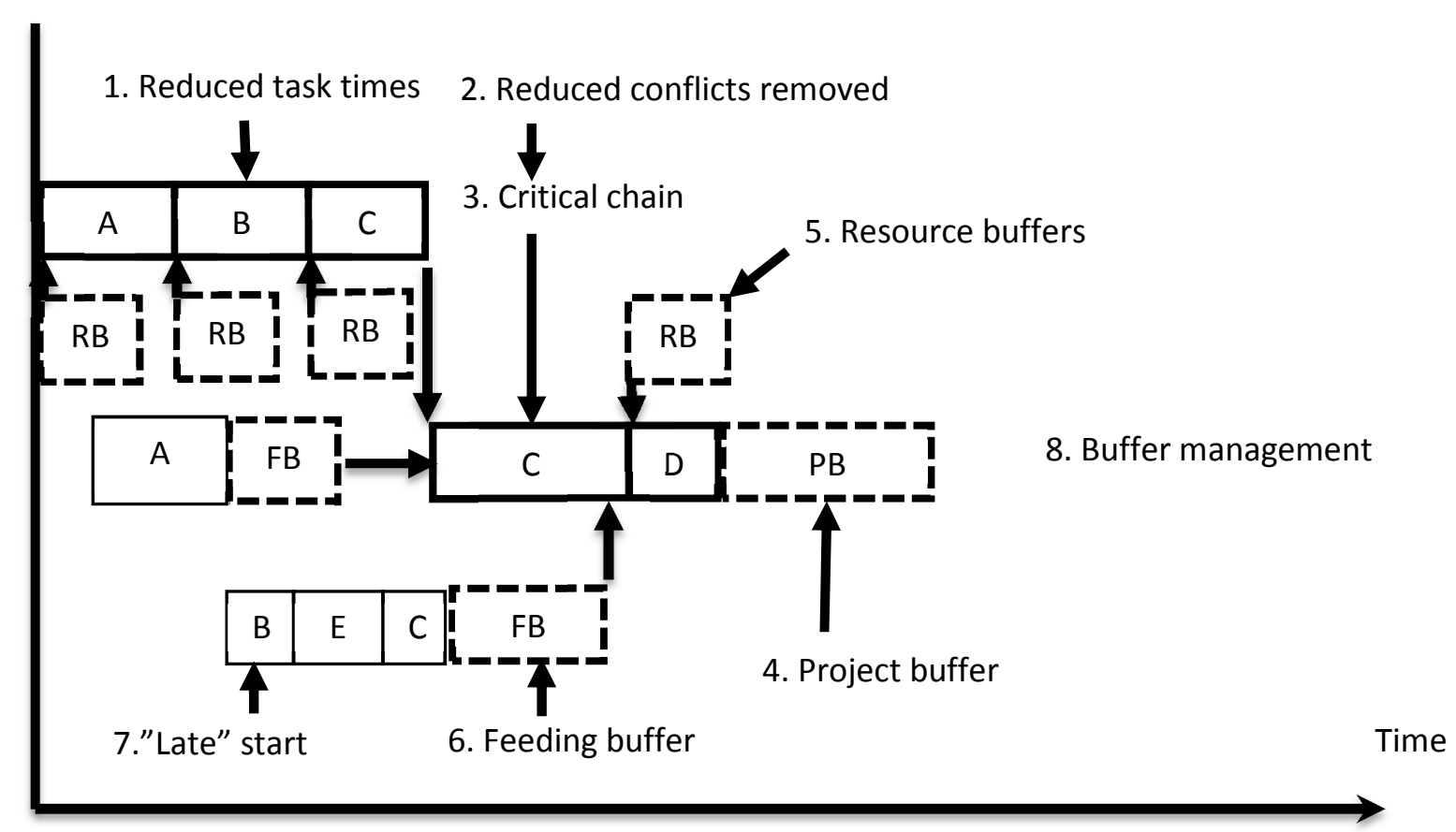

Figure 8: Key features of the critical chain project management system requirements (Adapted from Leach 2000). 


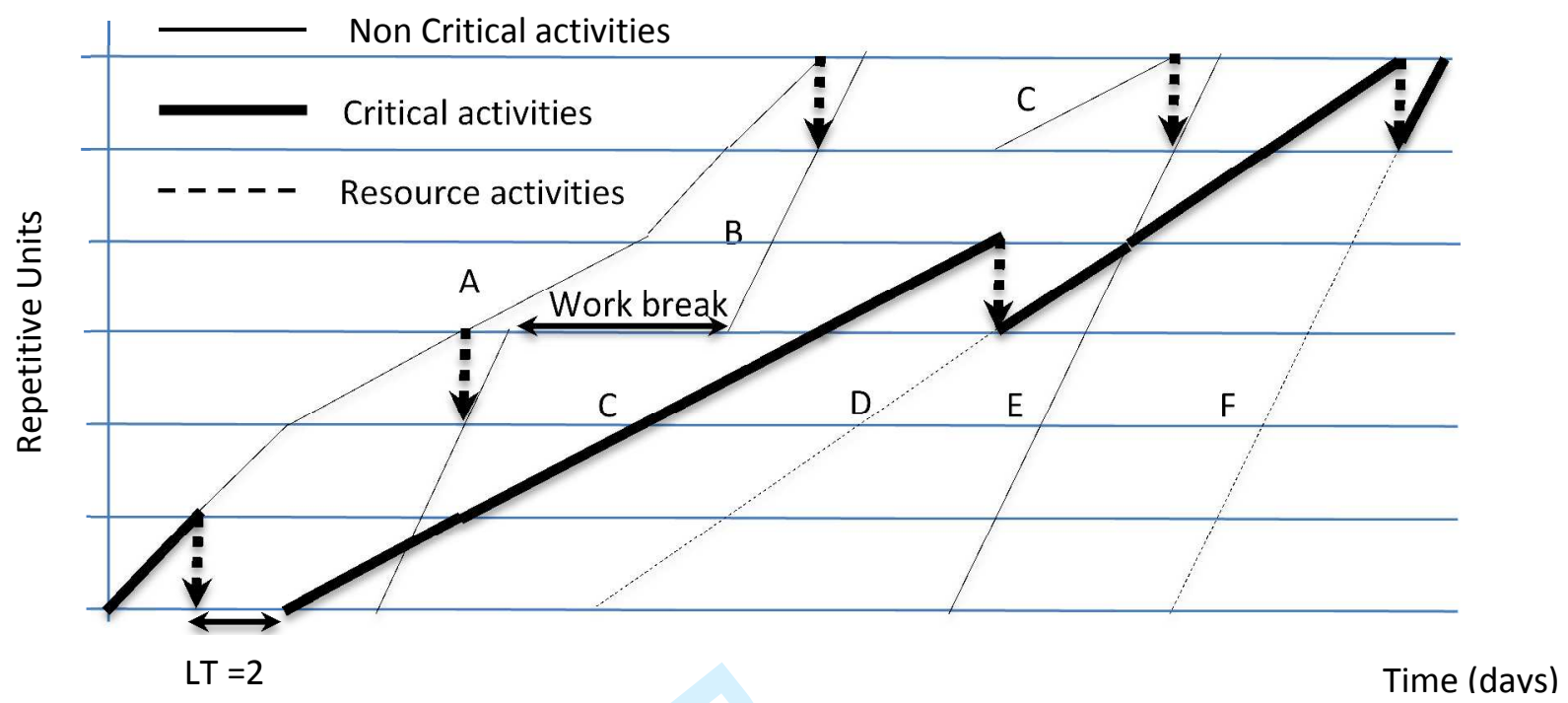

Figure 9: Identification of resource-critical activities. 


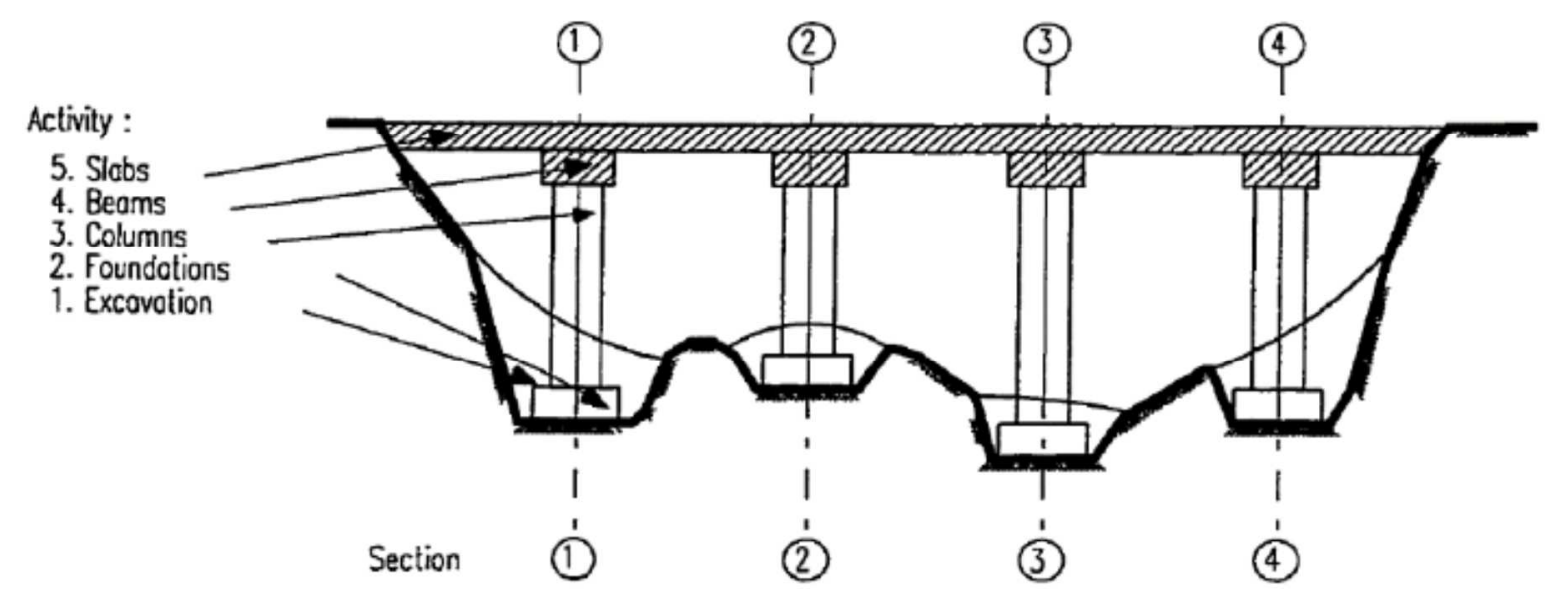

Figure 10: Three Span RC Bridge (Bakry 2014). 


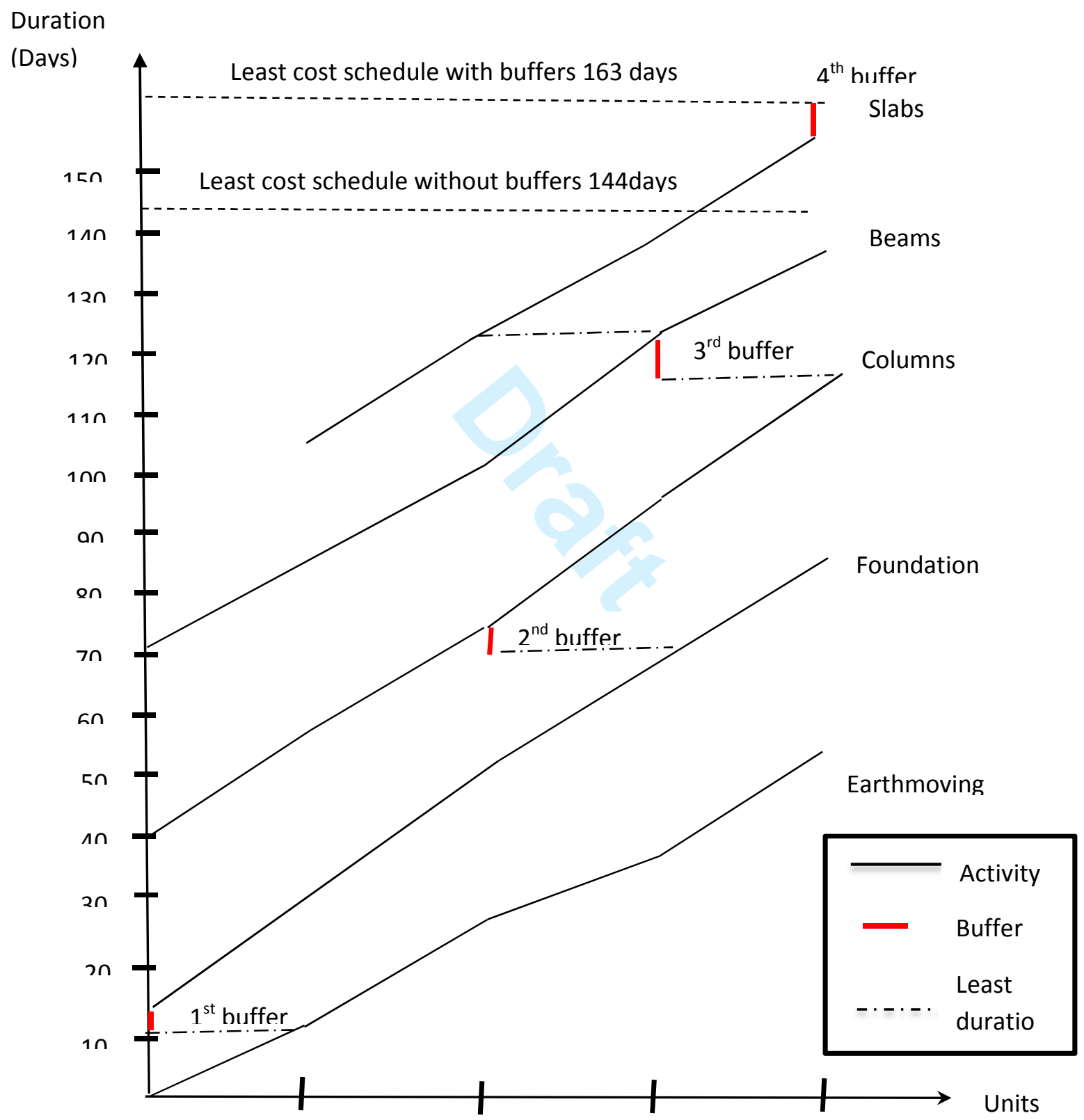

Figure 11: Defuzzified Schedule with Buffers (Adapted from Bakry 2014). 


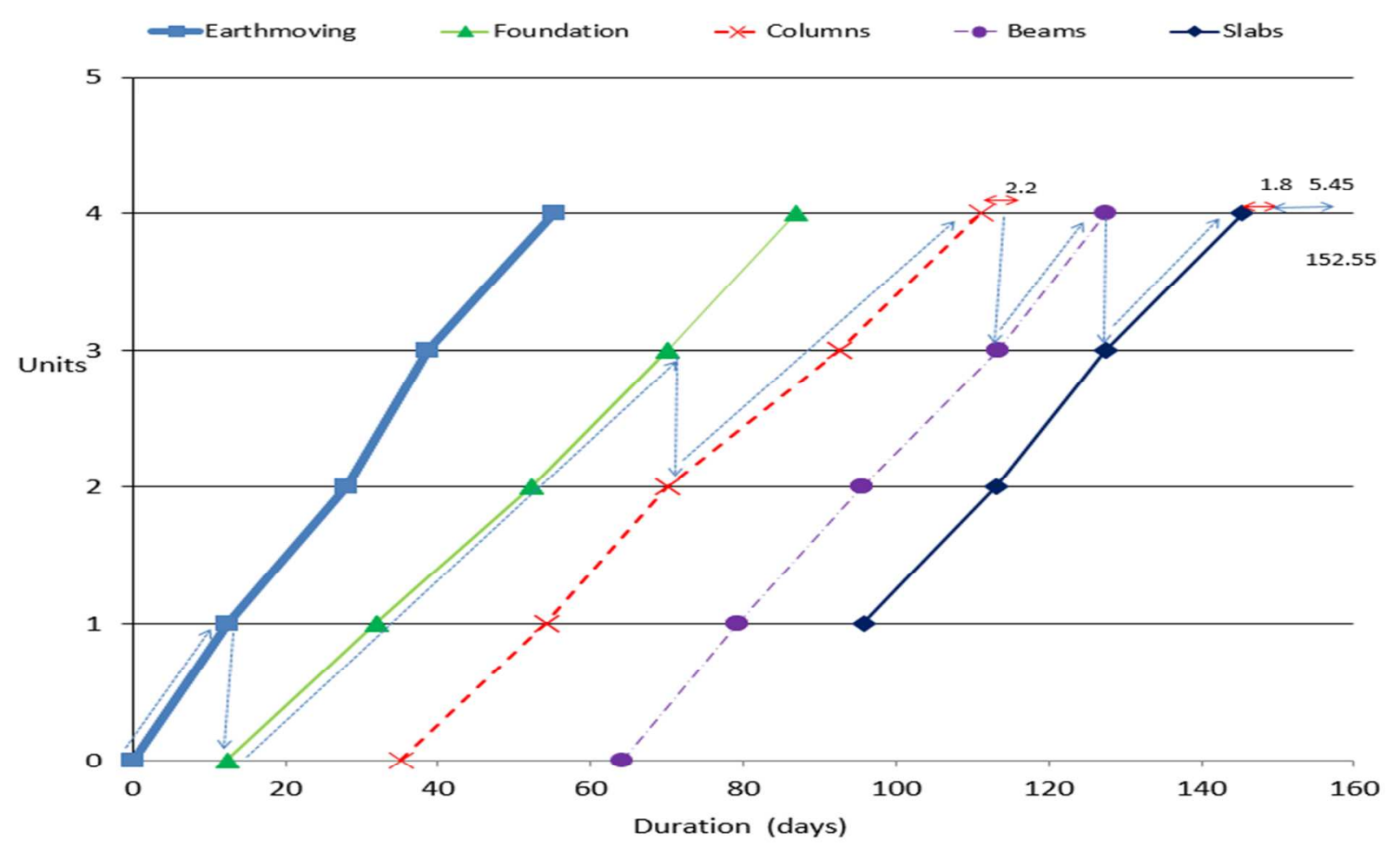

Figure 12: Integrated LSM and CCPM schedule. 


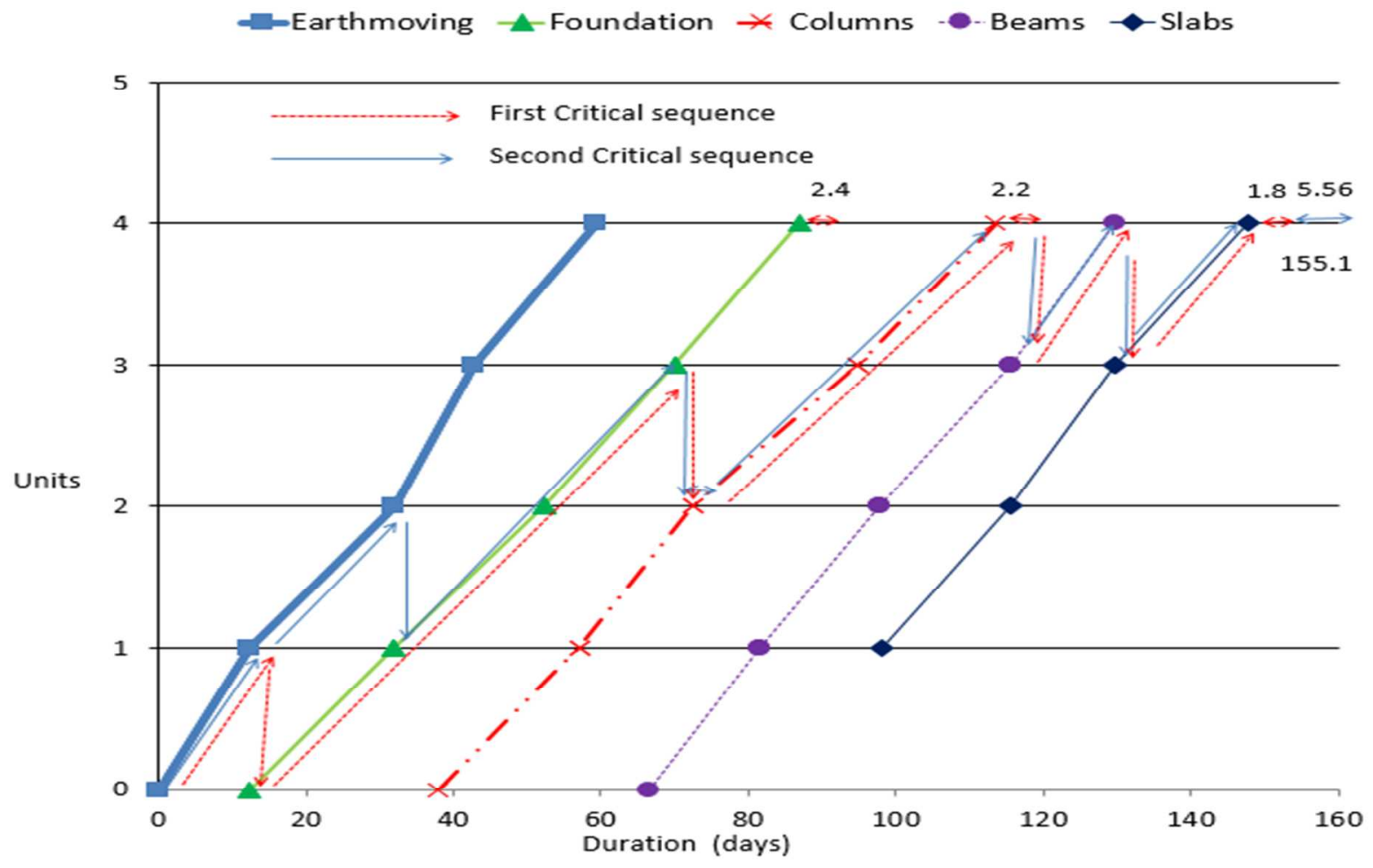

Figure 13: Critical sequence. 


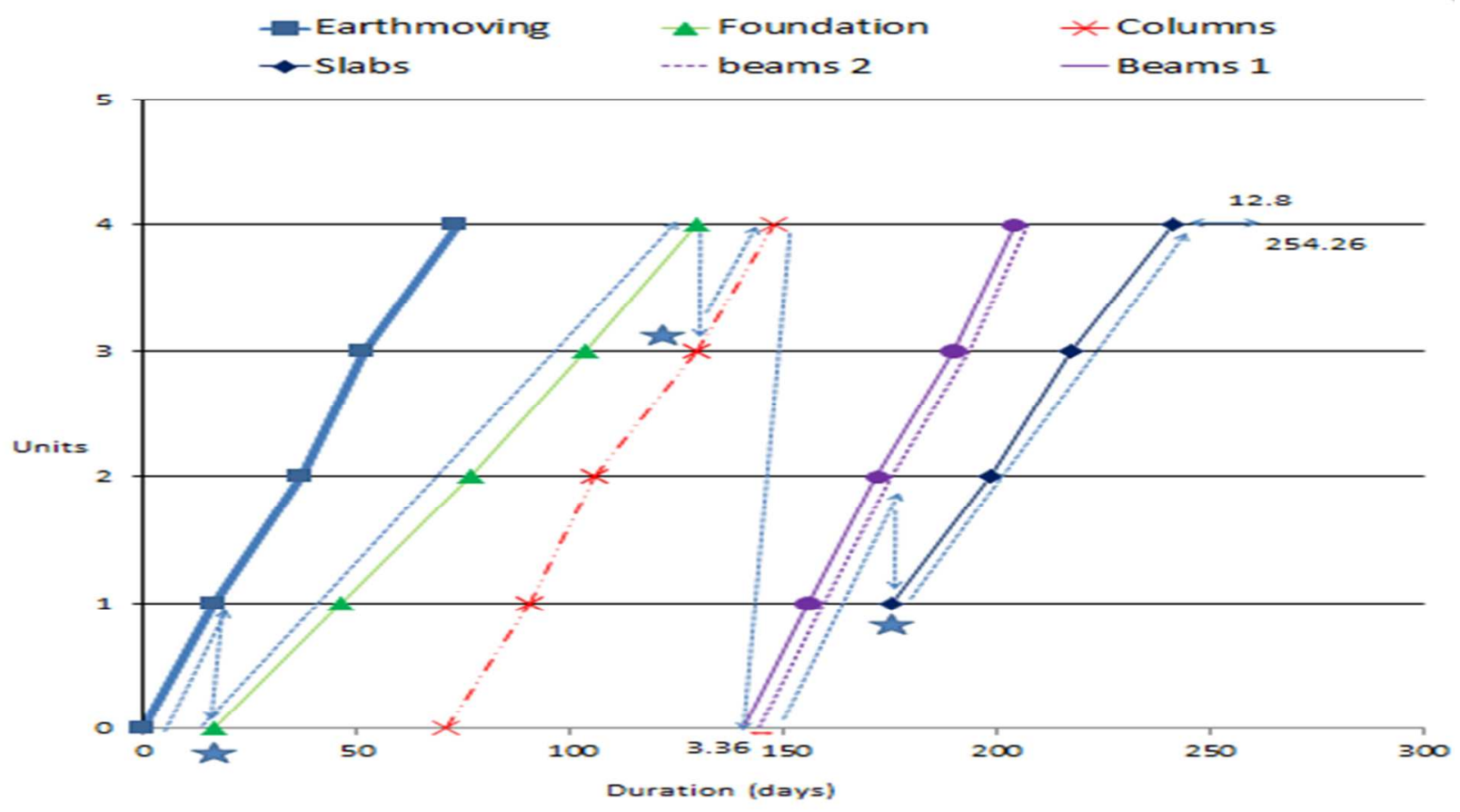

Figure 14: Critical sequence based on resources constraints. 